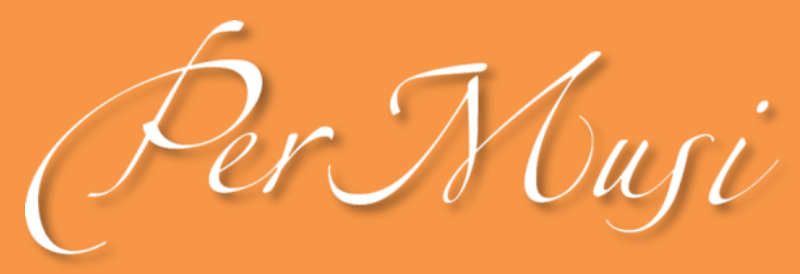

elSSN 2317-6377

\title{
As 30 teses sobre ensino musical escolar desenvolvidas no Brasil de 1998 até 2017
}

\author{
Eliton Perpetuo Rosa Pereira \\ http://orcid.org/0000-0002-9181-2543 \\ Instituto Federal de Goiás, Departamento de Áreas Acadêmicas 1 \\ eliton.pereira@ifg.edu.br
}

Carol Gillanders

http://orcid.org/0000-0001-7122-5416

Universidade de Santiago de Compostela, Departamento de Didáticas Aplicadas

carol.gillanders@usc.es

SCIENTIFIC ARTICLE

Submited date: 18 aug 2019

Final approval date: 04 jul 2021

Resumo: Esta pesquisa analisa o desenvolvimento da educação musical escolar como campo científico no Brasil. Após encontrarmos 300 teses de doutorado em educação musical defendidas no Brasil até 2017, realizamos um estudo de revisão da produção científica (Meta-análise e Síntese Qualitativa) das 30 teses que versam sobre o ensino de música na educação básica, o qual foi desenvolvido por meio da Análise de Conteúdo Categorial. Como resultado, apresentamos dados descritivos, agrupados por temas, subtemas, métodos de pesquisa e procedimentos de investigação, tendências didáticas e pedagógicas, epistemológicas e musicológicas. Ao final, apresentamos uma síntese dos temas, problemas e resultados das investigações de doutorado que abordam o ensino de música no contexto escolar brasileiro.

Palavras-chave: Educação musical; Brasil; Teses; Escola.

\section{TITLE: THE 30 THESES ON SCHOOL MUSIC TEACHING DEVELOPED IN BRAZIL FROM 1998 TO 2017}

Abstract: This research analyzes the development of school music education as a scientific field in Brazil. After finding 300 doctoral theses in music education defended in Brazil to 2017, we carried out a review study of the scientific production (Meta-analysis and Qualitative Synthesis) of the 30 theses that deal with the teaching of music in basic education, which was developed through the Categorical Content Analysis. As a result, we present descriptive data, grouped by themes, sub-themes, research methods and investigation procedures, didactic and pedagogical, epistemological and musicological trends. At the end, we present a synthesis of the themes, problems and results of the doctoral investigations that address the teaching of music in the Brazilian school context.

Keywords: Music Education; Brazil; Theses; School.

(9) (1) 


\section{As 30 teses sobre ensino musical escolar desenvolvidas no Brasil de 1998 até 2017}

Eliton Perpetuo Rosa Pereira, Instituto Federal de Goiás, eliton.pereira@ifg.edu.br Carol Gillanders, Universidade de Santiago de Compostela, carol.gillanders@usc.es

\section{Introdução}

Tendo por base as várias transformações pelas quais passou e tem passado a educação musical brasileira, desde o campo da Música e desde o campo da Educação, até sua obrigatoriedade no ensino básico (Brasil 2008), com posterior alteração (Brasil 2016), verificamos um significativo crescimento da influência da área com várias perspectivas para a formação humana por meio da música, envolvendo sua ampliação no contexto sociocultural, educativo e acadêmico ao longo dos séculos XX e XXI no Brasil. Entre essas várias mudanças encontram-se os avanços da área no contexto da produção científica, objeto de investigação deste estudo (Pereira 2019a). O avanço da educação musical no contexto universitário brasileiro é significativo, pois desde o final do século XX até o início do século XXI, a área da educação musical emergiu e construiu, nos últimos trinta anos, um significativo corpus de produção científica e artística.

Dois fatores pontuais justificam esta pesquisa, além da necessidade geral de conhecer a produção acadêmica crescente. Em primeiro lugar, a necessidade de examinar o 'Estado da Arte' da produção científica em educação musical, a partir da constatação de uma produção científica em cerca de 300 teses e mais de mil dissertações. Em segundo lugar, nos interessou conhecer e avançar em relação aos procedimentos de análise já implementados sobre a pesquisa em educação musical no Brasil. Análises essas que cessaram em 2013 (Fernandes 2007; Pires e Dalben 2013), as quais acompanhavam o desenvolvimento da produção científica na área, cujo modelo de análise também se alterou quando os pesquisadores passaram a estudar, de modo mais pontual, a produção da área por meio de análises por temas, subtemas, períodos, localidades ou periódicos específicos.

Tal é o desenvolvimento e produção da área, que hoje não há mais estudos abrangentes ou suficientes para abarcar toda a produção. Isto se deve ao desenvolvimento dos mais de cem cursos de Licenciatura em Música, aos dezenove cursos de mestrado e dez de doutorado em Música, ainda contando com as pesquisas sobre educação musical desenvolvidas em outras áreas, principalmente na Pós-Graduação em Educação. Contando ainda com o grande volume de Anais de eventos e de revistas científicas nacionais da área (Pereira 2017).

O objetivo geral deste estudo é analisar o desenvolvimento da educação musical como campo científico no Brasil, por meio da identificação, classificação e análise das investigações doutorais. Entre os objetivos específicos desta pesquisa, listamos: 
- Realizar uma busca sobre a investigação doutoral brasileira em educação musical a partir de meados do século XX;

- Estabelecer o marco atual dos temas de interesse da investigação em educação musical que podem constituir-se em linhas de investigação da área;

- Realizar uma síntese específica das concepções pedagógicas, das tendências musicológicas, dos problemas de investigação e dos resultados das pesquisas sobre educação musical escolar.

Com o patente desenvolvimento da educação musical no Brasil (Del-Ben 2013; Fernandes 2007), vários pesquisadores têm desenvolvido estudos que procuraram fazer vários tipos de levantamentos da produção científica em educação musical no país. Podemos citar, nesse contexto, os trabalhos de Fernandes (2007), Del-Ben (2013) e Tomás (2015). Estes dois pesquisadores inicialmente citados, foram os que mais contribuíram para esse tipo de pesquisa para a área. Já Tomás (2015), apesar de realizar sua análise no contexto da pesquisa em Música, contribui para compreendermos como a temática da educação musical esteve presente nos anais da Associação Nacional de Pesquisa e Pós-Graduação em Música - ANPPOM.

Em um estudo Meta-analítico sobre 300 teses encontradas no Brasil, defendidas de 1989 até 2017 (Pereira 2019a), identificamos 18 linhas investigativas mais presentes nas temáticas estudas no Brasil. Dentre essas linhas, destacamos a linha investigativa '10 - Escola de ensino básico e educação formal' como uma área que apresenta significativo interesse pelos pesquisadores da educação musical (Del-Ben 2013).

No Gráfico 01, a seguir, é possível visualizar as 295 teses (considerando cinco não encontradas) distribuídas entre as 18 linhas investigativas, com destaque para a linha 10, a qual ressaltamos nesta investigação.

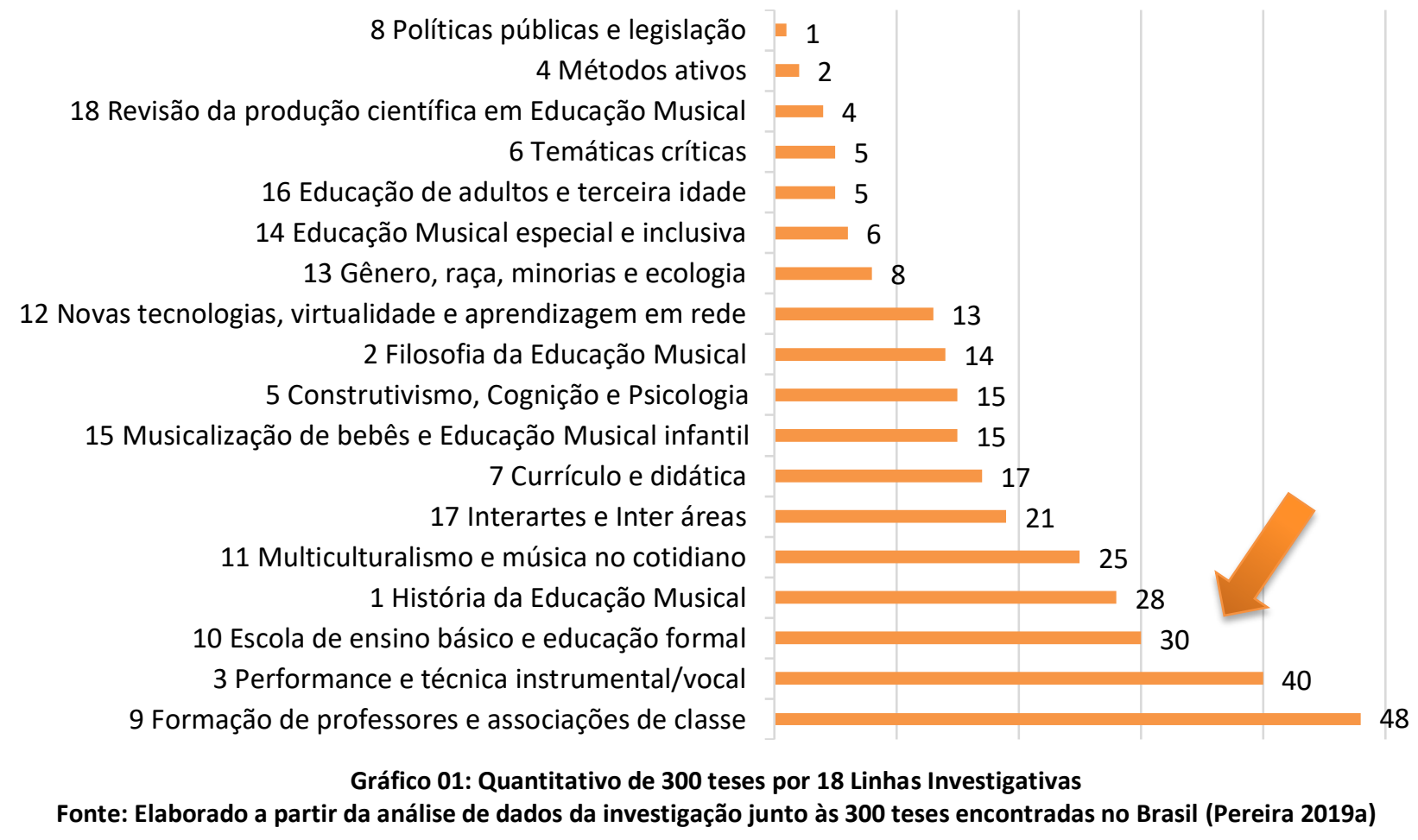

Identificamos a linha investigativa '10', que é caracterizada por tratar de questões que atravessam o ensino de música no contexto específico da escola de educação básica. No Brasil as temáticas interligadas com o ensino de música na escola ganharam força a partir da ampliação e do fortalecimento dos cursos de Licenciaturas, com posterior ampliação dos cursos de Pós-Graduação em Educação e em Música. Com o surgimento da ABEM (Associação Brasileira de Educação Musical) a partir da década de 1990, muitas 
transformações no campo das ações práticas, do contexto sociocultural, também passam a ser refletidas nas publicações da área.

A partir de um levantamento junto à revista da ABEM é possível compreender como a temática tem sido divulgada no Brasil. Sobre a temática de currículo e didática, na revista da ABEM encontramos em primeira mão os trabalhos de Pereira (2014), Mateiro (2009) e Sobreira (2014). Estes estudos tratam de questões vinculadas à formação de professores, de modo que os estudos estão ligados à formação inicial, formação continuada, prática docente, currículo e didática. Os estudos de Abreu (2015), Beineke (2000) e Penna (2002), são exemplos de pesquisas publicadas na revista da ABEM, que tratam especificamente de questões vinculadas à formação de professores para a docência na educação básica. De modo análogo, encontramos estudos voltados para a temática da legislação e das políticas públicas e sociais em educação musical, nas publicações de Aróstegui, Louro e Teixeira (2015), Arroyo (2004, 2015), Fernandes (2004) e Lima (2000). Além dessas pesquisas, aparecem também, de modo específico, as pesquisas sobre o ensino de música no contexto da educação básica. Sobre esta temática encontramos na revista da ABEM, os textos de Barbosa e França (2009), Beineke (2011), Galizia (2009), Penna (2008), Santos (2012) e Silva (2013).

Em uma investigação específica sobre a temática da educação básica no contexto das publicações da revista da ABEM, Del-Ben $(2013,129)$ encontrou "217 artigos publicados nos vinte números da Revista da ABEM entre 2000 e 2010", e isto "indica que 81 deles (37,3\%) tomam a educação musical escolar como objeto de estudo, de modo central ou periférico". Assim, verifica-se que esta temática é amplamente estudada no Brasil, cuja produção necessita de síntese - objetivando compreender os rumos investigativos relacionados.

\section{Metodologia}

O estudo foi desenvolvido com base nas metodologias de Estado da Arte (APA 2017), Meta-análise e Síntese Qualitativa (Cooper 2009; Cooper, Hedges e Valentine 2009; Major e Savin-Baden 2010) e também com a Análise de Conteúdo (Bardin 2011; Franco 2012; Bauer e Gaskell 2013). Foram elaborados formulários com agrupamentos de categorias (alguns com múltipla categorização), com o objetivo de proceder à análise das 30 teses. Esses formulários foram avaliados e validados por especialistas da área, o que está descrito no relatório completo da pesquisa (Pereira 2019a).

O levantamento das 30 teses $^{1}$ possibilitou uma maior profundidade analítica em virtude de ser uma temática já estudada no Brasil, sendo possível proceder também a uma comparação com a produção pregressa. Esta abordagem de revisão e comparação de resultados se enquadra no contexto metodológico da Síntese Qualitativa de Pesquisa ${ }^{2}$. Os trabalhos de Loureiro (2003), Mateiro e Souza (2014) e Fernandes (2016), em comparação com a teses da área, possibilita apresentar regularidades, diferenças, ou interpretações mais profundas sobre essa temática específica, de modo a contribuir para o avanço da pesquisa da área.

\footnotetext{
${ }^{1}$ Lista das 30 teses: <https://sites.google.com/view/educacaomusicalnobrasil> Acessível desde 2019.

${ }^{2}$ O objetivo desta metodologia, segundo Major e Savin-Baden (2010), é ajudar a compreender e sintetizar uma grande variedade de conjuntos de dados no contexto das ciências sociais, incluindo metodologias afins, como a Meta-Etnografia, Meta-Síntese, Síntese Interpretativa Crítica e Síntese Qualitativa.
} 
A seguir apresentaremos as informações codificadas a partir de agrupamentos de categorias por formulários de análises ${ }^{3}$.

- Formulário 01 - Identificação do autor, dados gerais e linhas investigativas;

- Formulário 02 - Dados intrínsecos(2i) e extrínsecos(2e) ao ensino-aprendizado;

- Formulário 03 - Subtemáticas da educação musical;

- Formulário 04 - Didáticas musicais;

- Formulário 05 - Concepções pedagógicas;

- Formulário 06 - Tendências musicológicas;

- Formulário 07 - Metodologias científicas empregadas;

- Formulário 08 - Objetivos, problemáticas e resultados;

No Quadro 01, a seguir, são apresentadas as principais categorias das teses pertencentes à linha investigativa '10 - Escola de ensino básico e educação formal'.

Quadro 01 - Categorias mais relevantes das teses pertencentes à linha investigativa '10 - Escola de ensino básico e educação formal'

\begin{tabular}{|c|c|c|c|c|c|c|}
\hline Autor(a) & Orientador(a) & Universidade & Área & Nível & Modalidade & PC* \\
\hline Beineke (2009) & Liane Hentschke & UFRGS & Música & Fundamental & Presencial & 20 \\
\hline Borges (2014) & Marisa Fonterrada & UNESP & Música & Fundamental & Presencial & 4 \\
\hline Campos (2008) & Eurize Pessanha & UFMGS & Educação & Fundamental & Presencial & 3 \\
\hline Cernev (2015) & Liane Hentschke & UFRGS & Música & Fundamental & Presencial & 3 \\
\hline Constantino (2017) & Juvenal Junior & UNESP & Educação & Fundamental & Presencial & 3 \\
\hline Costa (2015) & Isabel Frade & UFMG & Educação & Médio & Presencial & 2 \\
\hline Curtú (2011) & Denis D. Badia & UNESP & Educação & Fundamental & Presencial & 2 \\
\hline Fernandes (1998) & Mabel Oliveira & UFRJ & Educação & Fundamental & Presencial & 9 \\
\hline Ferreira (2016) & Cláudia Bellochio & UFSM & Educação & Fundamental & Presencial & 0 \\
\hline Ferreira (2017) & Mônica do Amaral & USP & Educação & Médio & Presencial & 1 \\
\hline Fialho (2014) & Jusamara Souza & UFRGS & Música & Médio & Presencial & 5 \\
\hline Figuerêdo (2014) & Luiz Magalhães & UFBA & Música & Médio & Presencial & 2 \\
\hline Lima (2005) & Vera Candau & PUC-RJ & Educação & Fundamental & Presencial & 12 \\
\hline Lopardo (2014) & Jusamara Souza & UFRGS & Música & Fundamental & Presencial & 3 \\
\hline Loureiro (2010) & Ângela Dalben & UFMG & Educação & Ed. Infantil & Presencial & 3 \\
\hline Marques (2015) & Luiz Magalhães & UFBA & Música & Fundamental & Presencial & 0 \\
\hline Mattos (2013) & Jaci Menezes & UFBA & Educação & Fundamental & Presencial & 6 \\
\hline Melo (2014) & Theresinha Miranda & UFBA & Educação & Fundamental & Especial & 7 \\
\hline Mendes (2010) & Aci Taveira Meyer & UNICAMP & Música & Fundamental & Presencial & 0 \\
\hline Meyer (2000) & Martha Destro & UNICAMP & Educação & Fundamental & Presencial & 0 \\
\hline Romanelli (2009) & Tânia Garcia & UFPR & Educação & Fundamental & Presencial & 9 \\
\hline Santos (2013) & Luciana Del Ben & UFRGS & Música & Fundamental & Presencial & 0 \\
\hline Santos (2017) & Pedro Rogério & UFC & Educação & Fundamental & Presencial & 1 \\
\hline Santos (2015) & Luciana Del Ben & UFRGS & Música & Médio & Presencial & 2 \\
\hline Serodio (2014) & Guilherme do Prado & UNICAMP & Educação & Fundamental & Presencial & 5 \\
\hline Silva (2009) & Jusamara V. Souza & UFRGS & Música & Fundamental & Presencial & 5 \\
\hline Soares (2015) & Mônica de A. Duarte & UNIRIO & Música & Fundamental & Presencial & 0 \\
\hline Souza (2015) & Alda de J. Oliveira & UFBA & Música & Fundamental & Presencial & 0 \\
\hline Targas (2009) & Ilza Z. L. Joly & UFSCar & Educação & Fundamental & Presencial & 1 \\
\hline Vertamatti (2012) & Marisa Fonterrada & UNESP & Música & Fundamental & Presencial & 2 \\
\hline
\end{tabular}

* PC = Produção científica baseada no trabalho de tese (artigos, capítulos e livros publicados pelos autores)

${ }^{3}$ Os dados da pesquisa foram comunicados em vários eventos científicos (Pereira 2017, 2018, 2019b). Para acesso às informações detalhadas sobre o processo de desenvolvimento e avaliação dos formulários de análise, verificar o relatório completo da pesquisa (Pereira 2019a). 


\section{Discussão e Resultados}

\subsection{Ampliação das Pesquisas Doutorais sobre Música na Escola: Temáticas e Didáticas}

A partir do formulário 01, apresentado anteriormente, foi possível identificar que nessa linha investigativa sobre o ensino de música na educação básica, as teses são majoritariamente dirigidas por orientadoras (25), em contraposição ao número de cinco orientadores. Em relação ao gênero dos(as) doutorandos(as), há nove teses desenvolvidas pelo gênero masculino e 21 pelo gênero feminino. Há significativa presença de programas de pós-graduação em Música e Educação da Universidade Federal do Rio Grande do Sul, seguida pela Universidade Estadual Paulista e Universidade Federal da Bahia. Na distribuição das teses por área de conhecimento, verifica-se que não há significativa diferença entre as áreas da Música e da Educação. Do total de trinta trabalhos encontrados, 16 foram desenvolvidos na pós-graduação em Educação e 14 na Música/Musicologia. Em relação ao nível educacional, verificou-se que há uma tese relacionada à educação infantil, cinco teses relacionadas ao ensino médio e 24 teses relacionadas à educação fundamental. Em relação à modalidade de ensino, 29 teses abordam a educação básica no ensino presencial, e somente uma aborda a educação especial (também presencial).

O Gráfico 02, a seguir, apresenta a produção de teses por ano, desde 1998 até 2017, no qual percebe-se que há um incremento de produção a partir de 2009.

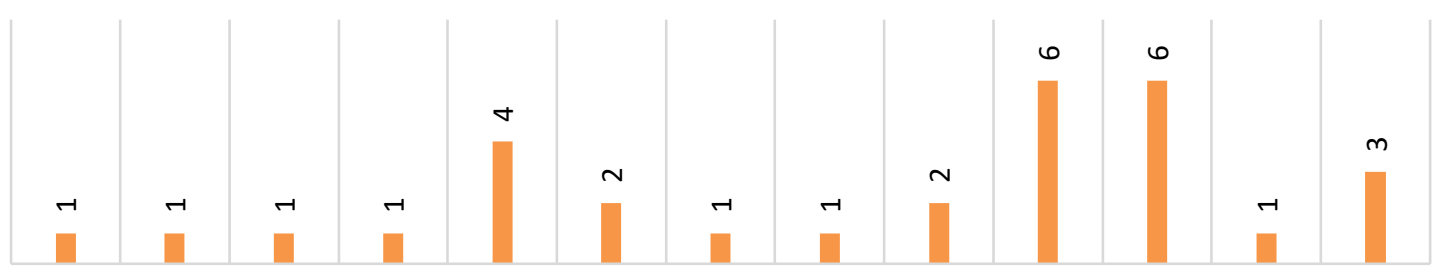

1998200020052008200920102011201220132014201520162017

Gráfico 02: Produção por ano para a linha investigativa '10 - Escola de ensino básico e educação formal'

O Gráfico 03, a seguir, apresenta a contagem de publicações oriundas das 30 teses. Nessa análise foram consideradas publicações em revistas científicas, capítulos de livros e livros completos publicados por cada autor de tese na mesma temática do trabalho da pesquisa doutoral. Este tipo de análise descreve a divulgação científica sobre a temática e possibilita compreender uma possível relação entre pesquisa e políticas de efetivação do ensino da música no contexto escolar.

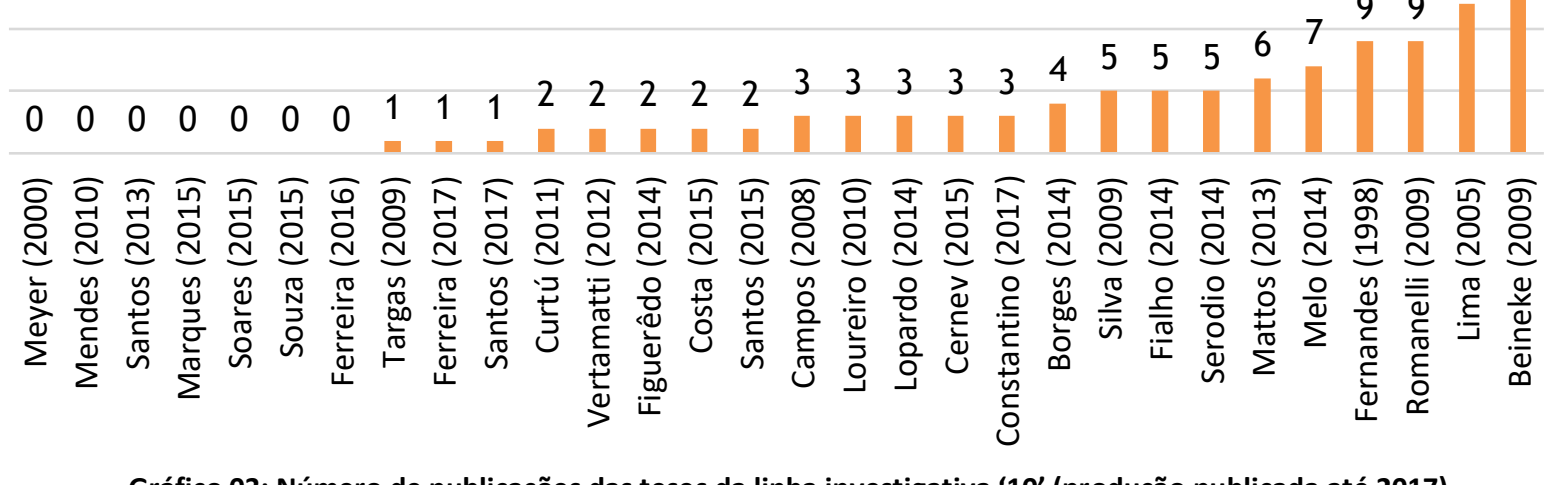

Gráfico 03: Número de publicações das teses da linha investigativa '10' (produção publicada até 2017) 
A Figura 01, a seguir, apresenta um dendograma que mostra a relação entre as 50 palavras mais frequentes nas 30 teses. Essa análise geral, por ser muito abrangente, serve para confirmar algumas das análises mais pontuais.

Figura 01: Dendograma de palavras das teses pertencentes à linha investigativa '10 - Escola de ensino básico e educação formal

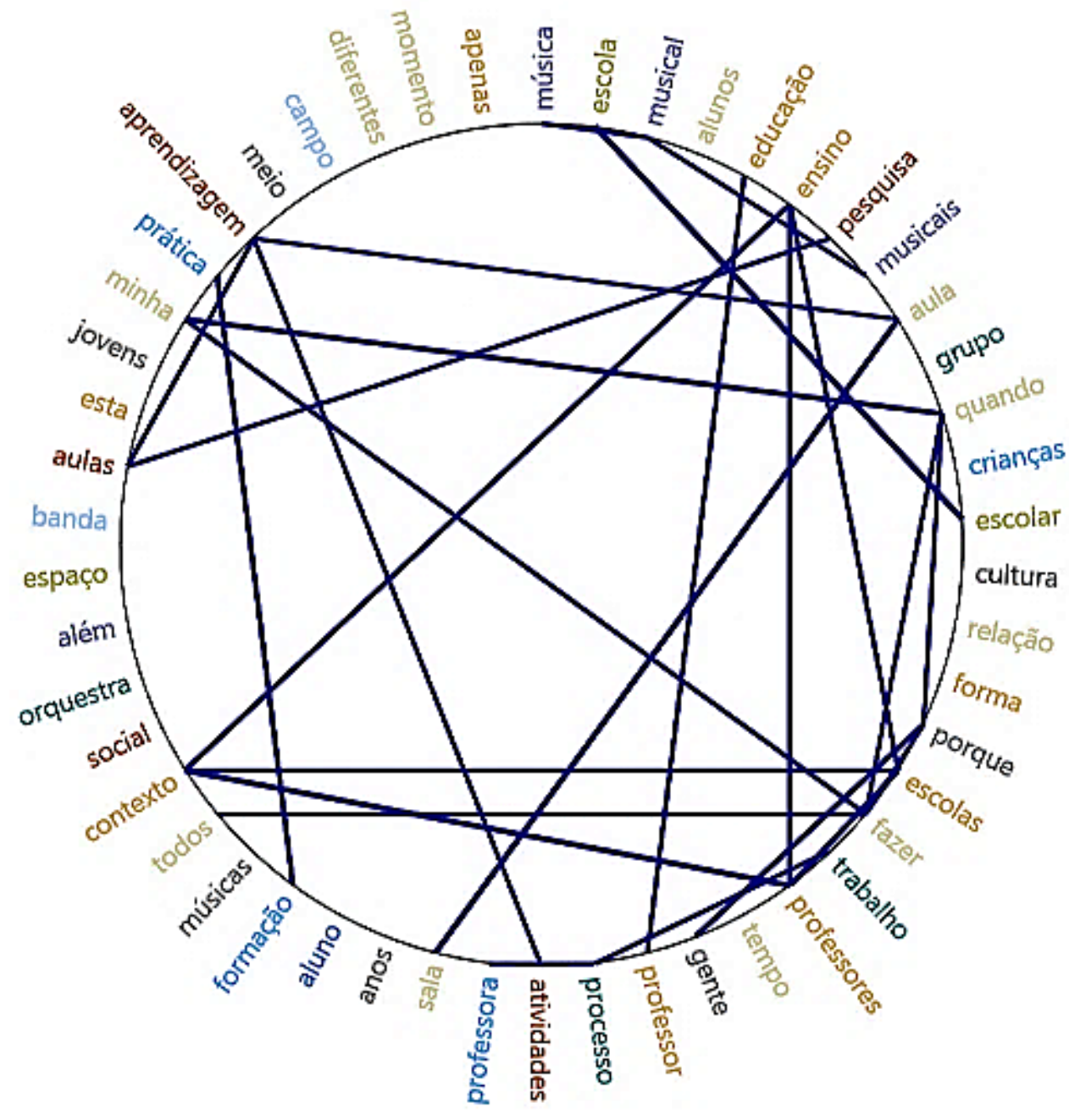

Por meio de uma análise dos agrupamentos de palavras é possível observar que o primeiro grupo faz referência aos jovens, ao contexto dos estudantes. Posteriormente, comparecem expressões ligadas ao meio cultural, bandas de música, músicas presentes neste contexto, orquestras, grupos musicais. Segue-se com o processo de ensino-aprendizagem, formação e prática de professores, a pesquisa qualitativa no contexto da investigação social, com foco nas aulas e nas atividades. Verifica-se, que há uma centralidade na figura dos estudantes, na sala de aula, nas atividades e no espaço escolar e seu contexto.

O Gráfico 04, a seguir, apresenta a distribuição das subtemáticas por ano. O ápice da produção foi nos anos de 2014 e 2015; com destaque para a subtemática 'Didática e prática educativa e projetos', que no caso, foi a que, além de apresentar maior número, também apresentou maior constância nos últimos vinte anos de produção aqui analisados.

\footnotetext{
${ }^{4}$ Dendogramas são estruturas gráficas utilizadas para representar as junções (métodos hierárquicos) ou divisões (métodos de partição) que ocorreram com base em valores provenientes da matriz de distâncias (Azambuja 2005).
} 


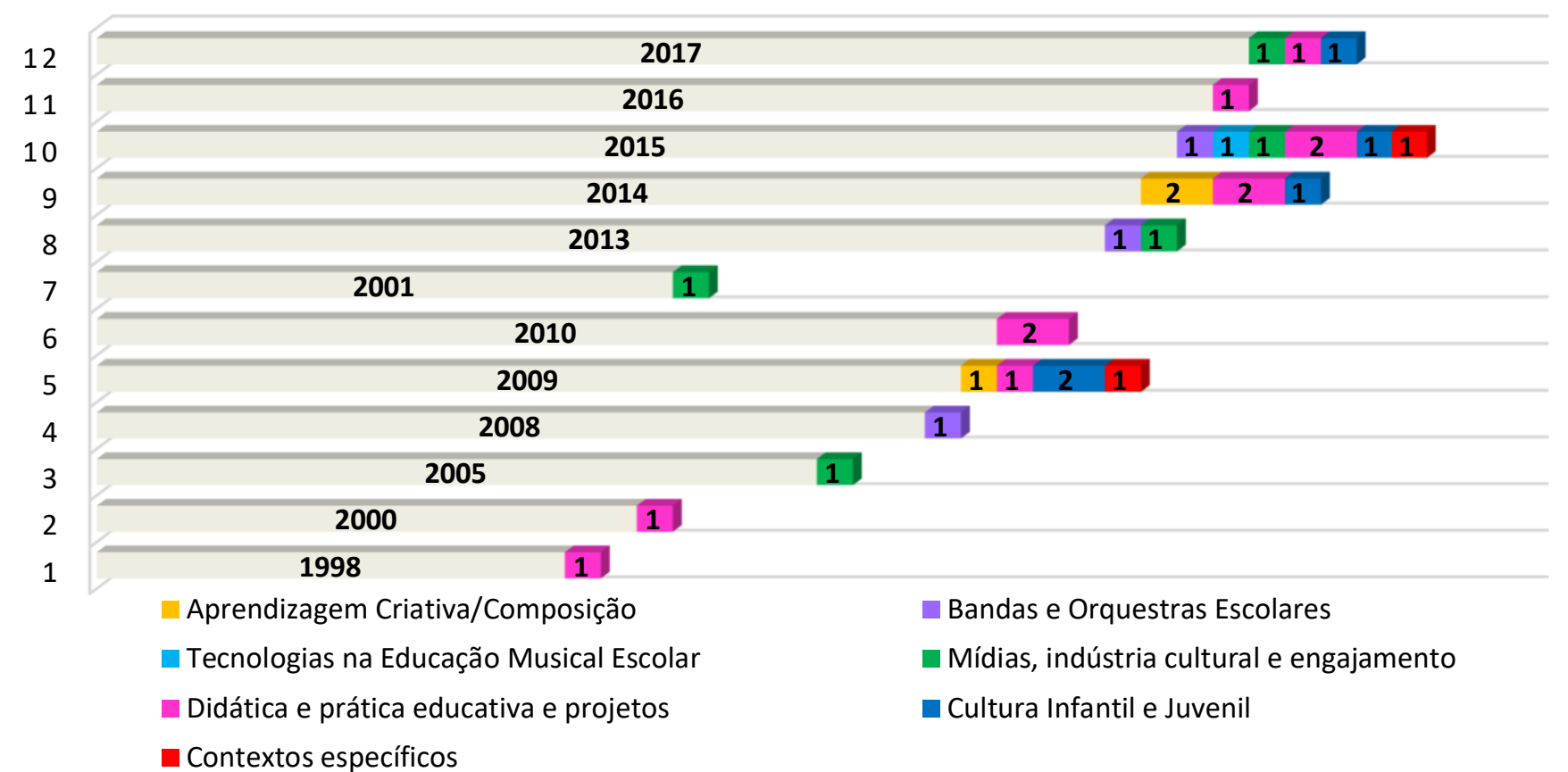

Gráfico 04 - Distribuição por ano das subtemáticas da Linha Investigativa '10 - Escola de ensino básico e educação formal'

O Gráfico 05, a seguir, apresenta as categorias do formulário 02 (elementos extrínsecos ao processo ensinoaprendizagem). Das 30 teses, mais da metade foi classificada como pertencentes à categoria 'Estrutura e funcionamento de organizações escolares', confirmando a predominância para o estudo de projetos, currículos, didáticas e práticas pedagógicas. Esta mesma relação é possível de ser observada no Gráfico 07, à frente, na categoria 'Métodos e técnicas de ensino de música (didática)' e 'Currículo'.

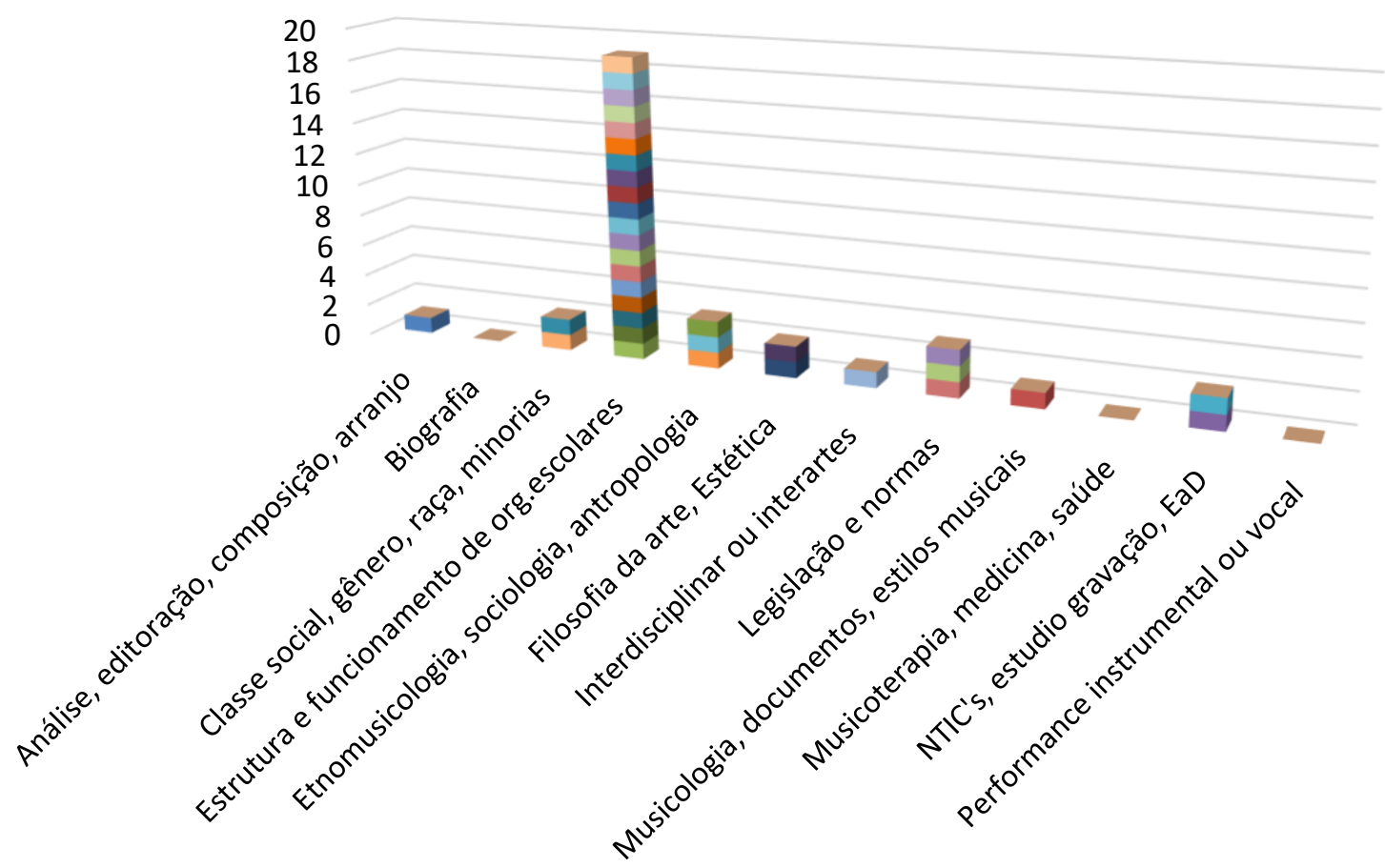

Gráfico 05: Categorias do formulário 02 (elementos extrínsecos ao processo ensino-aprendizagem)

No Gráfico 06, a seguir, é possível verificar que, pelo fato de termos retirado a categoria 'formação e prática de professores' para uma temática específica (em função de serem outras 48 teses - ver Gráfico 01), as 
demais categorias intrínsecas ao processo ensino-aprendizagem foram praticamente marcadas de modo igual, com exceção da categoria 'quem ensina', relacionada aos professores - com uma única tese identificada. Outra categoria que não apareceu nesta análise foi a relacionada ao desenvolvimento cognitivo e psicológico identificada por 'Quando (nível ou etapa)'.

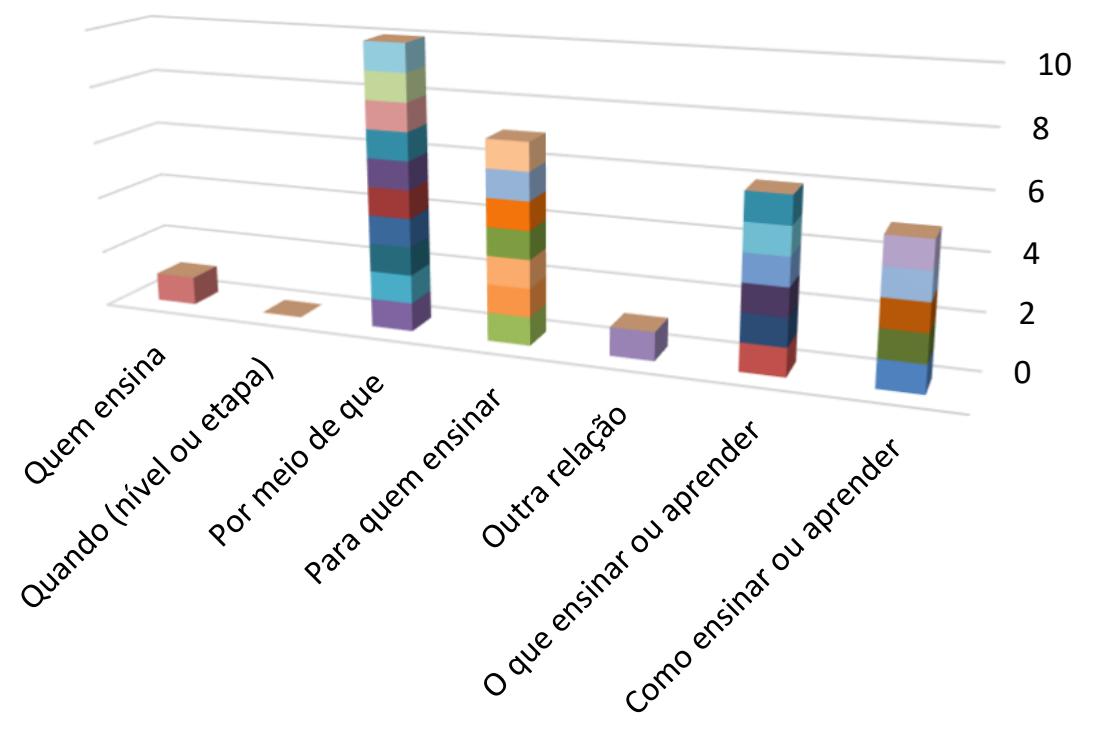

Gráfico 06: Categorias do formulário 02i (elementos intrínsecos ao processo ensino-aprendizagem)

No Gráfico 07, a seguir, além das categorias mais marcadas já comentadas, vale ressaltar a categoria 'Sociologia, etnomusicologia e multiculturalismo', vinculadas no Gráfico 04 à 'Cultura infantil e juvenil'.

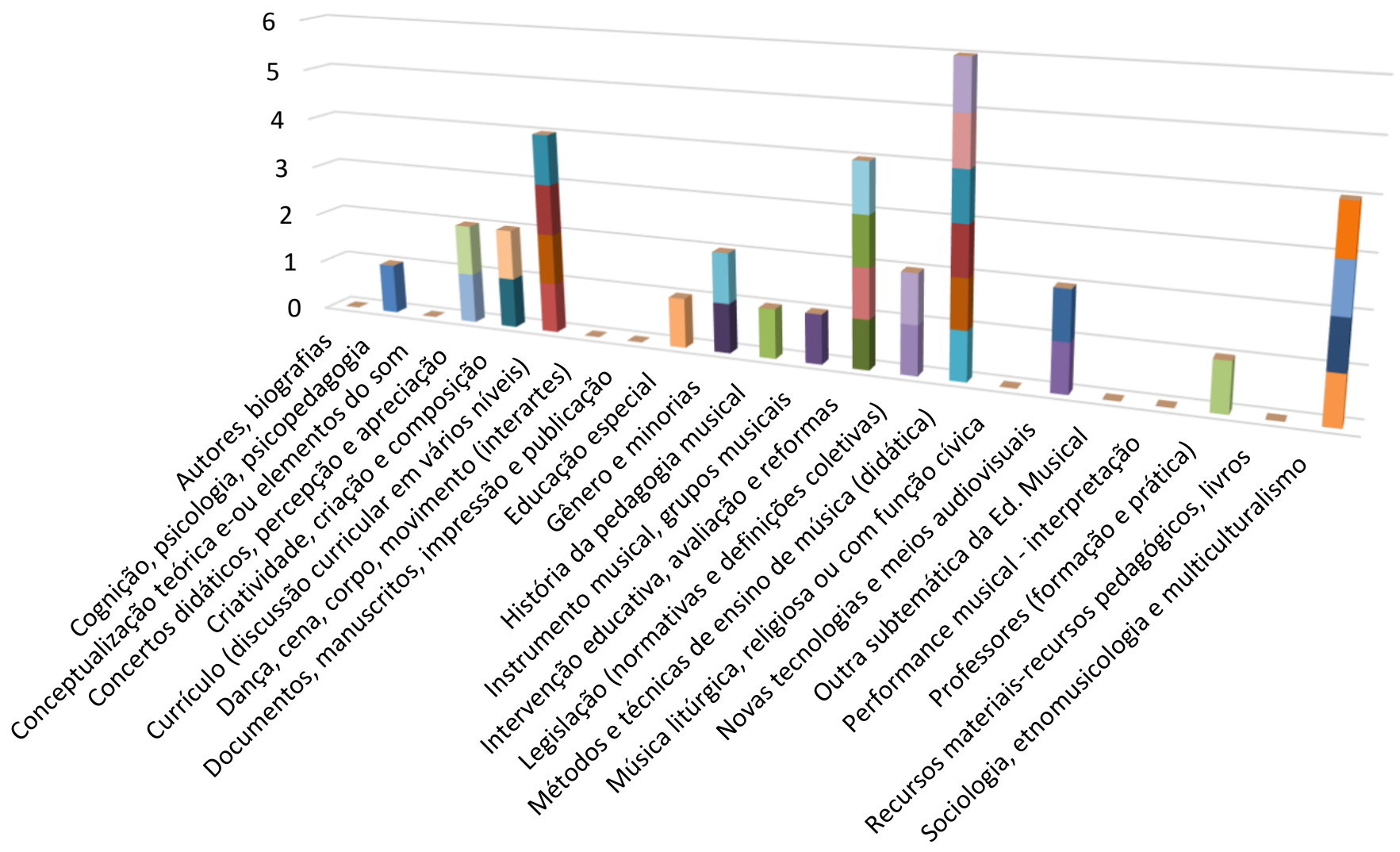


O Gráfico 08, a seguir, apresenta as categorias marcadas do formulário 04 (didáticas musicais). As didáticas musicais, que além de separar as categorias críticas e criativas, também separa as categorias tecnicistas de metodologias - estando esta última mais relacionada às bandas e orquestras escolares.

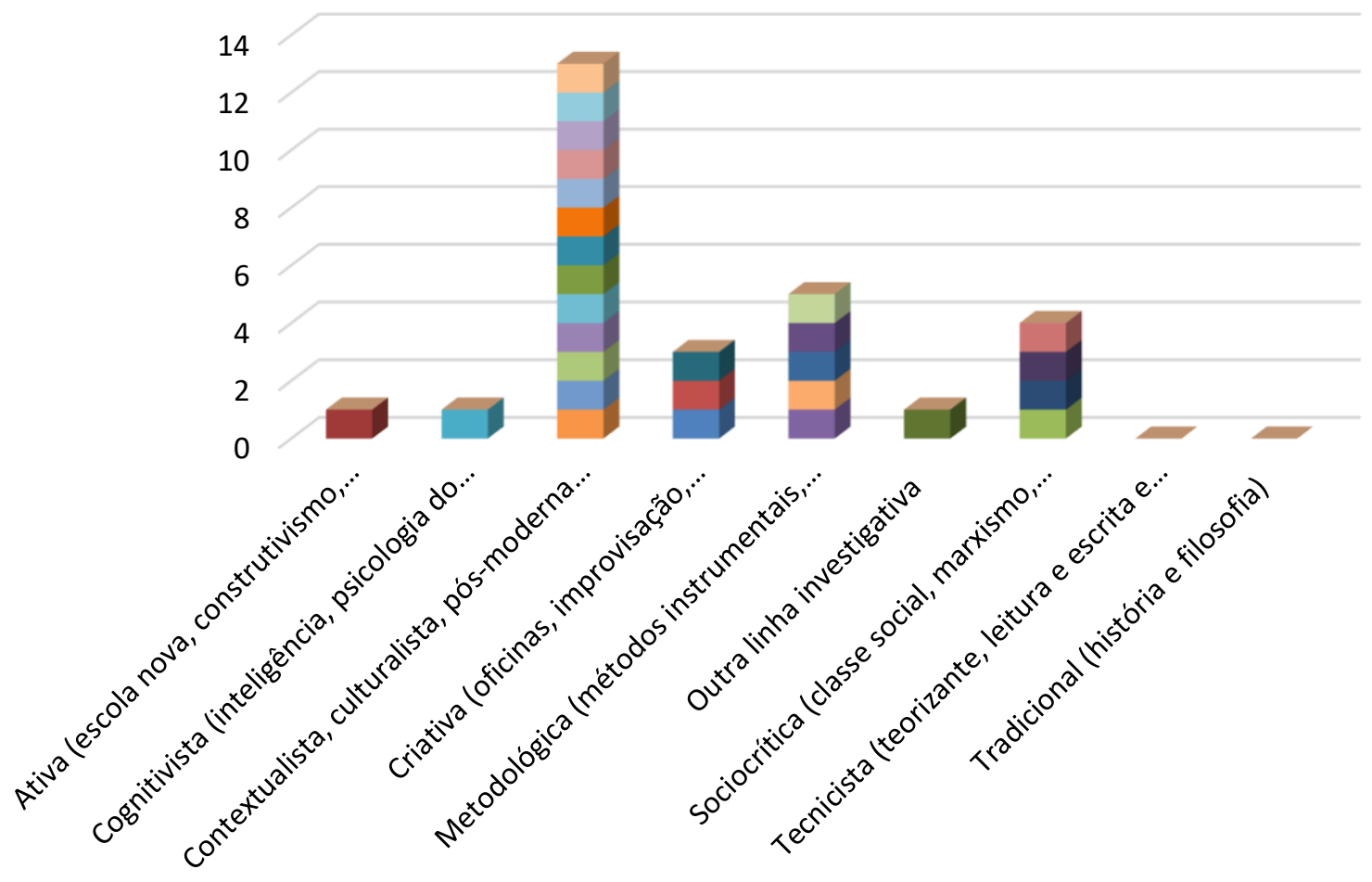

Gráfico 08: Categorias do formulário 04 (didáticas musicais)

Verifica-se que os formulários 02(e) e 03 se apresentaram neste processo de exploração temática das teses como aglutináveis e complementares, podendo estas categorias pertencerem a um mesmo agrupamento. Vale ressaltar a necessidade de uma maior definição sobre as classificações temáticas e subtemáticas das teses a partir destes formulários de análises construídos para este estudo exploratório/descritivo.

\subsection{Pedagogias, Musicologias e Metodologias das Investigações sobre educação musical}

\section{Escolar}

No Gráfico 09, a seguir, é possível verificar a distribuição das classificações nas teses por concepções pedagógicas, no qual a categoria mais marcada foi a pós-moderna, que indica teses com foco em temáticas pós-estruturalistas ou neopragmatistas, cujas temáticas envolvem gênero, raça, minorias, ou a descrição de práticas pedagógico-musicais vivenciadas na escolar.

A segunda concepção pedagógica mais marcada foi a crítica reprodutivista cujas temáticas são abordadas de forma a expressar um posicionamento crítico, porém desvinculado de propostas de mudança social ou cultural. Esta concepção "é reprodutivista porque suas análises chegam invariavelmente à conclusão que a função básica da educação é reproduzir as condições sociais vigentes” (Saviani 2013, 393).

A terceira categoria mais codificada foi a fenomenológica que se trata de uma concepção pedagógica voltada para a descrição de fenômenos educativos, comportamentos, práticas e ações no contexto escolar. Sendo o foco da fenomenologia o lugar de primazia do sujeito no processo de relação com o mundo ou com o objetivo investigado (Magrini 2012). 
Somente quatro teses foram classificadas como pertencentes à categoria crítica social dos conteúdos ou histórico-crítica, por compreenderem o processo educativo como um ato político e comprometido com a mudança social (Libâneo 1985).

Quatro teses foram identificadas como neocognitivistas, outras duas são sociocríticas e outras três foram divididas em três categorias: racional tecnológica (ligada às novas tecnologias), liberal renovada ou escola nova, e holística.

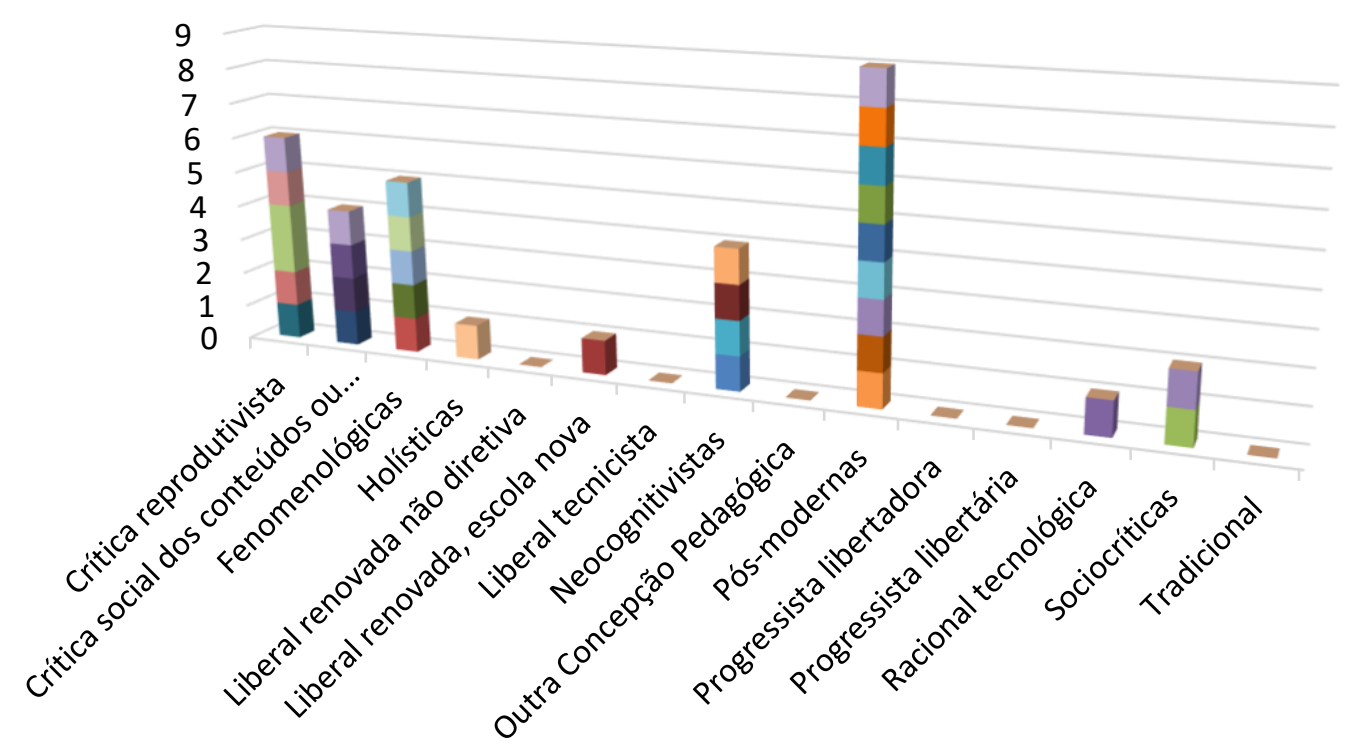

Gráfico 09: Categorias do formulário 05 (concepções pedagógicas)

Com a finalidade de demostrar melhor a classificação das teses nestas concepções pedagógicas identificadas, optamos por trazer algumas citações das teses para clarear sua relação com os autores estudados (Libâneo 1985, 2010; Saviani 2013), que tratam sobre as diferentes concepções pedagógicas que convivem no campo educativo musical brasileiro. Vale ressaltar a necessidade de relacionar estas concepções pedagógicas com o contexto das categorias específicas da educação musical e com a prática pedagógica dos professores e das escolas (Pereira 2020).

Por esta razão consideramos realizar esta categorização especificamente nas teses que abordam a educação musical na escola de educação básica. Procurando aproximar este estudo de investigações anteriormente desenvolvidas sobre concepções pedagógicas na prática dos professores, mas também considerando que estas concepções se manifestam nas teses, nas abordagens teóricas e metodológicas dos investigadores. Ou seja, o foco da análise se dá sobre a concepção pedagógica do investigador, seu modo de olhar e interpretar o ensino de música na escola, e não sobre o contexto escolar estudado exclusivamente (Sánchez e Gamboa 2012).

Em relação à concepção pedagógica pós-moderna, por exemplo, tal abordagem busca superar o positivismo e o tradicionalismo, valorizando as experiências pessoais dos sujeitos e a interação dialógica. Libâneo e Santos $(2010,40)$ explicam que "não se trata de buscar a verdade estabelecida, mas de criar significados nas interações dialógicas", pois "é pela experiência, pelo diálogo, pela conversação, que os participantes fazem escolhas racionais, que são pessoais, históricas, vinculadas a uma situação concreta". Assim, no contexto educacional, são valorizados: os diálogos e as comunicações, os contextos e as vivências culturais, a 
construção do conhecimento prático e a transformação pessoal dos participantes. Ainda que sejam concepções essencialmente epistemológicas, os autores compreendem esses modos de interpretação da realidade como concepções pedagógicas, ou seja, se trata de uma configuração epistemicopedagógica ${ }^{5}$.

No Gráfico 10, a seguir, as teses foram classificadas em quatro principais categorias da musicologia/etnomusicologia ${ }^{6}$ :

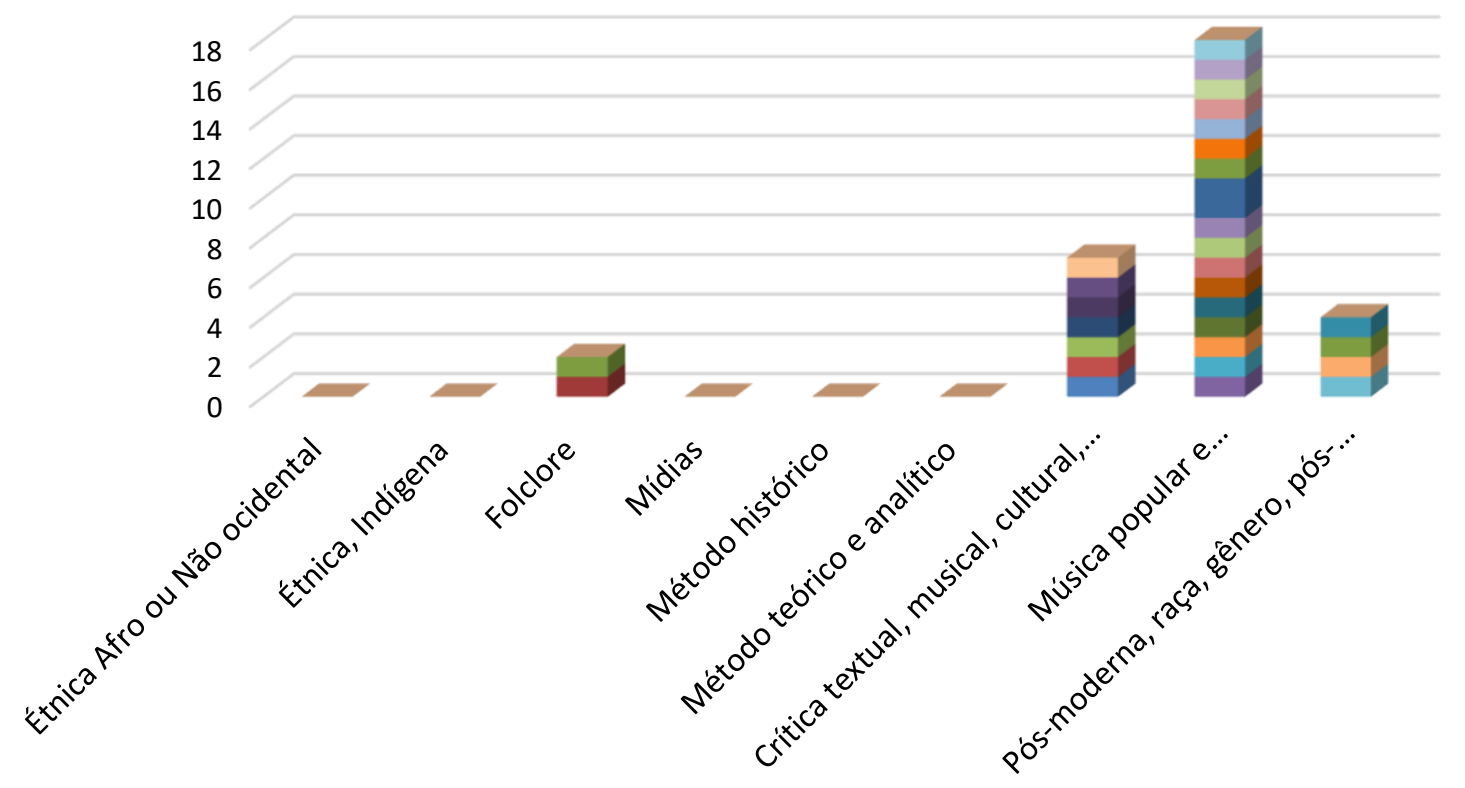

Gráfico 10: Categorias do formulário 06 (tendências musicológicas)

Não é comum os estudos fazerem essa relação entre musicologia e educação musical, principalmente em contextos de análise comparativa que se utilizam das vertentes da Musicologia como categorias a serem consideradas nos processos analíticos qualitativos. No entanto, considerando as fundamentações musicológicas, a base para esta relação é bem segura a partir dos trabalhos de Nettl (2010) e Swanwick (1992).

A classificação das teses foi feita com base em citações que expressam como os pesquisadores concebem a música, no que diz respeito ao conceito de música, seu vínculo com algum tipo de estética, função social ou gênero/estilo musical. Tendo em conta a tendência como uma disposição ou convergência para um determinado contexto musical/cultural, também considerando a relação entre o título do trabalho, o resumo, e partes do texto que expressam essas disposições.

A grande maioria das investigações, 60\%, 18 de 30 teses, foram classificadas em 'Música popular e multiculturalismo'. Outras oito teses, $26,6 \%$ do total de 30 , foram classificadas em 'Crítica textual, musical, cultural, social'. Quatro teses foram classificadas com tendência musicológica 'Pós-moderna, raça, gênero, pós-estruturalismo' e somente uma tese como 'Etnomusicologia ou Musicologia comparada, antropologia e etnografia/folclore'.

\footnotetext{
${ }^{5}$ Fazendo referência à expressão de Almeida e Tello $(2013,15)$, que definem epistemetodologia como "categoria na qual confluem a apresentação do método e a posição epistemológica do pesquisador."

${ }^{6} \mathrm{O}$ formulário foi construído com base nos referenciais da área: Adler (apud Dudeque 2004), Duckles, V., Pasler, J., Stanley, G., Christensen, T., Haggh, B. H., Balchin, R., Libin, L. et al (1980), Duckles e Pasler (2001), Ibarretxe (2006) e Solomon (2015).
} 
A seguir serão apresentadas análises sobre aspectos relacionados com as metodologias de pesquisas empregadas nas teses. Consideramos autores que abordam a estrutura metodológica em pesquisa científica: Filho e Gamboa (2013), Sampieri, Collado e Lucio (2013), e Souza e Magalhães (2011).

Os itens considerados como pertencentes à estrutura da metodologia científica foram: 1) Abordagem metodológica; 2) Epistemologia científica; 3) Metodologia de pesquisa; 4) Procedimentos metodológicos. No Gráfico 11, a seguir, são apresentados os quantitativos de teses por abordagem metodológica: qualitativa, quantitativa ou mista.

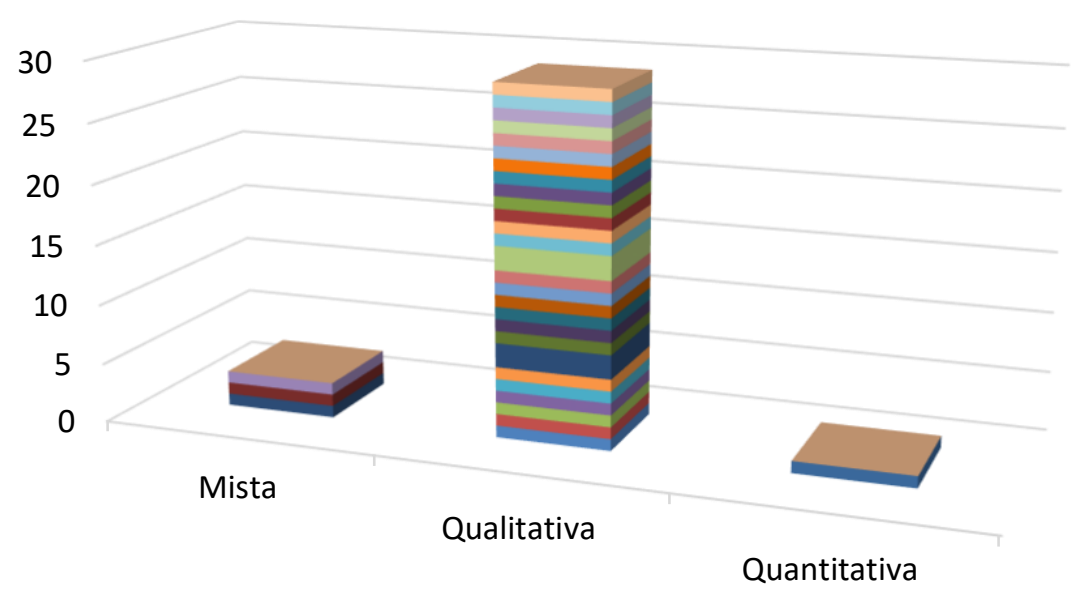

Gráfico 11: Categorias do formulário 07a (abordagens metodológicas)

Sampieri, Collado e Lucio (2013) demonstram procedimentos para estudos quantitativos, de modo que consideramos como abordagem metodológica quantitativa, somente aquelas teses que apresentam uma lógica dedutiva com controle estatístico de variáveis.

O Gráfico 12, a seguir, mostra a distribuição dos estudos por epistemologia cientifica, no qual é possível observar que a maioria dos estudos foram classificados como pertencentes ao método epistemológico 'Pósmoderno' e à 'Fenomenologia'. Sete teses foram consideradas 'Críticas' e duas 'Positivistas'.

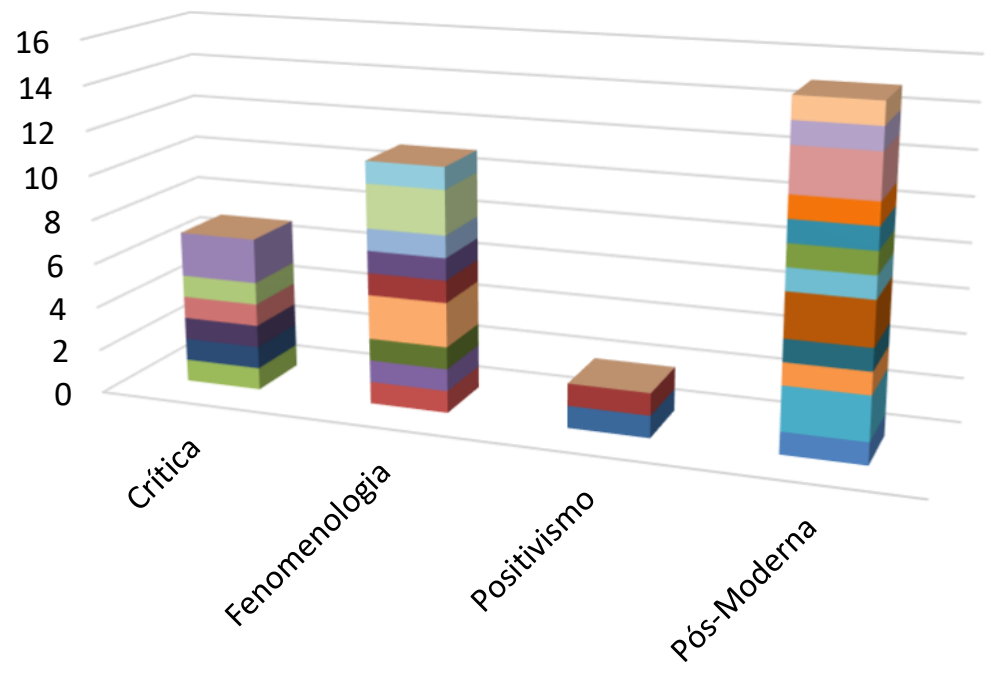

Gráfico 12: Categorias do formulário 07b (epistemologia científica) para as teses pertencentes à Linha Investigativa '10'

\footnotetext{
${ }^{7}$ Categorias do formulário 07: 07a abordagem metodológica, 07b epistemologia científica, 07c metodologias de pesquisa e 07 c procedimentos metodológicos.
} 
Sanchéz Gamboa (2012) e Souza e Magalhães (2011), são exemplo de pesquisadores que abordam classificação das epistemologias científicas nas investigações em ciências sociais. A análise desenvolvida por esses pesquisadores, considera que a investigação científica apresenta rigor metodológico na medida em que toda a estrutura da pesquisa se vincula ao método epistemológico adotado na investigação.

Nesse sentido, o grande número de trabalhos classificados como pertencentes à epistemologia científica Pós-moderna e Fenomenológica certamente revela uma tendência de transição entre os extremos apresentados pelas epistemologias Positivistas e Críticas. Por outro lado, apesar de haver esta classificação no estudo, os(as) autores(as) das teses nem sempre assumem, de modo explícito, estas concepções, o que exige densa análise dos textos, sendo que esta temática necessita ser mais discutida pela área.

O Gráfico 13, a seguir, apresenta a classificação das teses para a categoria que identifica a metodologia de pesquisa. Verifica-se que as metodologias de pesquisa mais encontradas foram: Pesquisa participante, Estudo de caso, Estudo etnoGráfico e Pesquisa-ação. Ainda comparecem em menor número: Pesquisa documental, e Pesquisa quase-experimental. $O$ item 'outra metodologia' e 'outro procedimento metodológico de pesquisa', que se refere basicamente a metodologia não identificada ou ainda ao tratamento de coleta e análise de dados com base em testes de percepção sonora/musical. Esses testes foram identificados em algumas teses, como em Fernandes (2016), que além das avaliações de percepção, também realiza análise das composições musicais dos participantes.

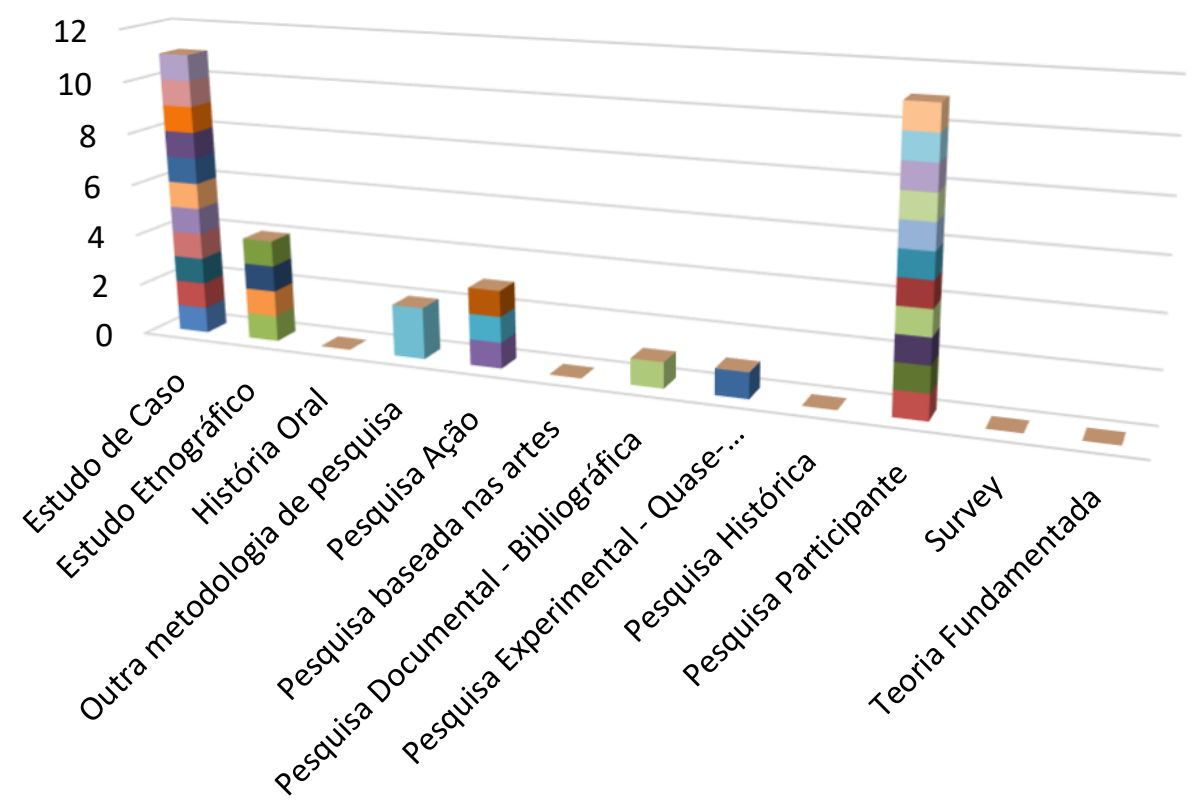

Gráfico 13: Categorias do formulário 07c (metodologias de pesquisa) para as teses da Linha Investigativa '10'

O Gráfico 14, a seguir, apresenta a classificação das teses para a categoria 'procedimentos metodológicos'. Os outros procedimentos metodológicos utilizados: pré-teste e pós-teste de percepção sonora/musical e análise de composições musicais por júri composto por músicos experientes, são procedimentos próprios da área da educação musical. O primeiro está ligado à metodologia experimental ou quase-experimental e o segundo a abordagens metodológicas mais qualitativas. 


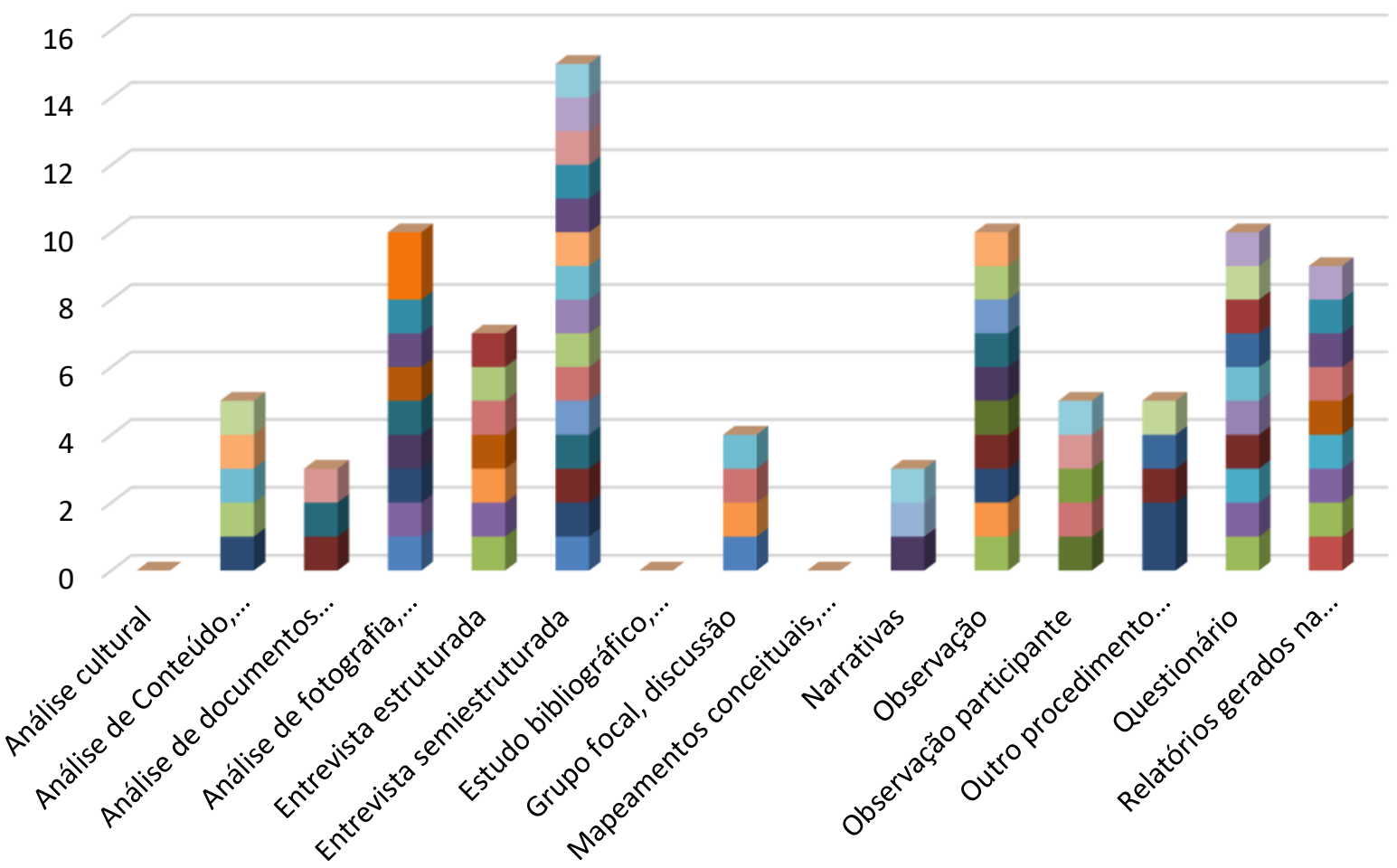

Gráfico 14: Categorias do formulário 07d (procedimentos metodológicos) para as teses pertencentes à Linha Investigativa '10 - Escola de ensino básico e educação formal'

Os formulários de 01 a 07 possibilitaram desenvolver várias análises descritivas. Já o formulário de análise 08 possibilitou um exame mais detalhado sobre as problemáticas de investigação em comparação com resultados das investigações das teses da Linha Investigativa '10 - Escola de ensino básico e educação formal'. Os trechos codificados das teses foram divididos em dois grupos, um primeiro grupo referente à construção do objeto de pesquisa e um segundo relativo às conclusões ou indicações de resultados.

Essa análise qualitativa objetivou compreender as relações entre estrutura 'problemática/resultados', e compreender de modo sistemático os elementos que compõe as origens das pesquisas, as categorias, teorias e suas relações ante as conclusões. Assim, apesar de não haver hipótese a priori, procuramos verificar essas relações tendo em conta as várias análises já elaboradas sobre as teses.

Em termos comparativos, para possibilitar a síntese qualitativa de pesquisa (Cooper 2009; Cooper, Hedges e Valentine 2009; Major e Savin-Baden 2010), verificou-se problemáticas comuns e resultados descritivos, críticos ou propositivos, que apontam direções comuns ou complementares da área na investigação sobre essa temática específica.

Entre as principais categorias, temáticas e recomendações das teses 'Contextualistas, culturalistas, pósmodernas' podemos listar:

- Narrativas, Culturas, Identidades e Socialização de Jovens;

- Educação musical no ensino médio e suas peculiaridades;

- Relação entre a cultura musical interna e externa à escola;

- Repensar a cultura como parte do processo formativo escolar;

- Considerar a música do cotidiano extraescolar e no cotidiano escolar;

- Cultura musical infantil no contexto escolar; 
- Desenvolvimento de didáticas musicais com base nas culturas infantis;

- Práticas socioculturais e pedagógicas de grupos musicais escolares;

- Qualificar os processos pedagógico-musicais dos jovens;

- Repensar a relação professor-aluno no atual contexto multicultural e tecnológico;

Entre as principais categorias, temáticas e recomendações das teses Críticas, podemos listar:

- Priorizar o processo de aprendizagem em detrimento do treinamento;

- Priorizar a aquisição do conhecimento do conteúdo musical;

- Priorizar a música como linguagem;

- Considerar o interesse e necessidade das crianças;

- Assegurar instrumentos musicais de qualidade para as aulas;

- Necessidade de criação e manutenção de corporações musicais escolares;

- Denunciar o silencio criativo e a padronização musical impostos pela mídia;

- Oportunizar a criação, a autoria e o fazer musical direto pelos estudantes;

- Dar voz aos estudantes pertencentes às minorias, ao negro, ao índio;

- Resgatar a cultura negra e étnicas que foram silenciadas pelo tempo;

- Possibilitar a conscientização de questões sociais e culturais por meio do engajamento juvenil;

- Propor modelos flexíveis para a inserção da educação musical nas escolas.

Entre as principais categorias, temáticas e recomendações das teses fenomenológicas, podemos listar:

- Permitir aos educandos a criação musical individual e coletiva;

- Valorizar a subjetividade, sensibilidade e a criação interartística, interdisciplinar;

- Explorar os processos terapêuticos e transformativos da música na escola;

- Buscar alternativas tecnológicas do ciberespaço para produção musical;

- Incluir deficientes e com necessidades especiais nos processos educativos;

- Explorar e usar métodos de musicalização consolidados no contexto escolar;

- Valorizar a orquestra, banda e coral como espaços genuínos na escola;

- Questionar o sentido atribuído à educação musical no contexto escolar;

- Considerar os elementos intrínsecos e extrínsecos ao processo de ensino-aprendizagem musical;

- Promover o engajamento dos sujeitos em processos composicionais e criativos;

- Buscar a articulação entre artistas e instituições de arte com a escola;

- Buscar articulação entre ações musicais juvenis internas e externas à escola;

\section{Considerações Finais}

Considerando as sínteses realizadas, identificamos recomendações gerais das investigações doutorais que versam sobre o ensino musical escolar, com destaque para o papel da criatividade, da sensibilização sonora, dos processos interculturais, das corporações musicais escolares e para a consideração da linguagem musical como conhecimento. Percebemos que as análises categoriais mais descritivas foram importantes para compreendermos o sentido dessas sínteses realizadas a partir de uma leitura mais detalhada dos textos.

De modo paralelo à essa caracterização, se compararmos o nível da produção científica dos investigadores da área da educação musical escolar no Brasil (Gráfico 03, anteriormente apresentado), veremos que esta 
subárea específica necessita avançar para exercer maior influência no contexto científico/acadêmico, e consequentemente no contexto social.

Nesse processo de análise das produções científicas é necessário ressaltar o papel das pesquisas de Estado da Arte e de Síntese Qualitativa de Pesquisa, enquanto meios de compreensão do desenvolvimento e impacto da área na sociedade. Cooper (2009), Cooper e Hedges (2009), Major e Savin-Baden (2010), e Souza e Magalhães (2011), entre outros autores contemporâneas da área da pesquisa em educação e ciências sociais, contribuem metodologicamente para a área avançar com base em investigações de sínteses qualitativas, como as de Araújo e Toscano (2013), Del-Ben (2013) e Pires e Dalben (2013) que apresentam estudos de revisão da produção científica em educação musical e sobre os quais é possível construir outras investigações, a fim de comparar seus resultados e propor novos estudos de revisão no contexto da pesquisa em educação musical no Brasil. Assim, percebemos que a depender dos referenciais teóricos e metodológicos, as pesquisas de revisão podem apresentar diferentes modos de percepção do estado da arte da investigação.

Outro elemento a ser grifado na análise das teses é a ausência da discussão mais clara sobre Musicologia/Etnomusicologia em relação com a educação musical, partindo da concepção de que a educação musical se constitui na intersecção entre Música e Educação, entre Musicologias e Pedagogias. Nesse contexto também identificamos alguns modismos temáticos, teóricos e metodológicos nem sempre totalmente adequados ao atendimento às problemáticas das pesquisas.

Por outro lado, referente às concepções didáticas da área e às concepções pedagógicas, verificamos que os pesquisadores procuram superar a dualidade entre tendências liberais e progressistas, de modo que as pesquisas desenvolvidas - quase que totalmente dentro da abordagem qualitativa - apresentam um relativo compromisso de transformação social vinculado aos contextos de cada investigação.

Acredita-se que o conjunto de categorias usadas para o desenvolvimento dessas análises, juntamente com a proposta de síntese qualitativa das produções, pode colaborar com o desenvolvimento de novas pesquisas sobre a produção da área. Verificamos que a produção científica em educação musical no Brasil exige novas abordagens de estudo e metodologias mais diversificadas nos processos de análise, isso em função do significativo desenvolvimento da área como campo de conhecimento.

\section{Referências}

Abreu, Delmare Vasconcelos de. 2015. "Narrativas de profissionalização docente em música: uma epistemologia política na perspectiva da Teoria Ator-Rede". Revista da ABEM 23 (34): 125-137.

Almeida, Maria de Lourdes P. de, e Cesar Tello. 2013. "Consolidando o campo da investigação em política educacional". In Estudos epistemológicos no campo da pesquisa em política educacional. Organizado por Cesar Tello e Maria de Lourdes P. de Almeida, 9-24. Campinas, Mercado de Letras.

APA. 2017. Que es el estado del arte. Site espanhol da Associação de Psicologia Americana. Disponível em: <http://normasapa.net/que-es-el-estado-del-arte> Dez. 2017.

Araújo, Katia da Silva Ribeiro, e Carlos Toscano. 2013. "As pesquisas em educação musical no período de 2001 a 2102". Artigo apresentado no II Seminário Internacional de Representações Sociais, Subjetividade e Educação - II SIRSSE e IV Seminário Internacional Sobre Profissionalização Docente SIPD/Cátedra Unesco, Curitiba, setembro 31232-31245. 
Aróstegui, José Luís, Ana Lúcia Louro, e Ziliane L. de O. Teixeira. 2015. "Las políticas educativas de reforma y su impacto en la Educación Musical Escolar. De dónde venimos y hacia dónde podemos ir". Revista da ABEM 23 (35): 24-34.

Arroyo, M. 2004. "Música na educação básica: situações e reações nesta fase pós-LDBEN/96". Revista da ABEM 10: 29-34.

Arroyo, M. 2015. “O conteúdo música e jovens estudantes nas políticas educacionais e curriculares das redes públicas do estado e da cidade de São Paulo (2007-2013)". Revista da ABEM 23 (34): 58-79.

Azambuja, Sandro de. 2005. "Estudo e implementação da análise de agrupamento em ambientes virtuais de aprendizagem". Dissertação de mestrado em Informática. Universidade Federal do Rio de Janeiro.

Barbosa, Karla Jaber, e Cecília C. França. 2009. "Estudo comparativo entre a apreciação musical direcionada e não direcionada de crianças de sete a dez anos em escola regular". Revista da ABEM 7 (22): 7-18.

Bardin, Laurence. 2011. Análise de conteúdo. São Paulo: Edições 70.

Bauer, Martin W., e George Gaskell. 2013. Pesquisa Qualitativa com texto, imagem e som: um manual prático. 11a ed. Petrópolis - RJ: Editora Vozes.

Beineke, Viviane. 2000. "Teoria e prática pedagógica: encontros e desencontros na formação de professores". Revista da ABEM 5: 87-98.

Beineke, Viviane. 2011. "Aprendizagem criativa na escola: um olhar para a perspectiva das crianças sobre suas práticas musicais". Revista da ABEM 19 (26): 92-104.

Brasil. 2008. Lei № 11.769, de 18 de agosto de 2008. Disponível em: <http://www.planalto.gov.br/ccivil_03/_ato2007-2010/2008/lei/l11769.htm> Ago. de 2019.

Brasil. 2016. Lei № 13.278, de 2 de maio de 2016. Disponível em: <http://www.planalto.gov.br/ccivil_03/_Ato2015-2018/2016/Lei/L13278.htm\#ART1> Ago. de 2019.

Cooper, Harris. 2009. Research Synthesis and Meta-Analysis: a step-by-step approach. 4 Edition. San Antonio: Sage Publications Ltd.

Cooper, Harris, Larry V. Hedges, end Jeffrey C. Valentine. 2009. The Handbook of Research Synthesis and Meta-Analysis. New York: Russel Sage Foundation.

Del-Ben, Luciana M. 2013. "Modos de pensar a educação musical escolar: uma análise de artigos da revista da ABEM". Inter Meio - Revista do Programa de Pós-Graduação em Educação 37 (19): 125-148.

Duckles, Vicent, end Jann Pasler. 2016. "Musicology - The nature of musicology". In New Grove Dictionary of Music and Musicians. Edited by Deane Root. Oxford: Oxford University Press. Available in: <https://www.oxfordmusiconline.com/grovemusic/> Dez. 2016.

Duckles, Vicent, Jann Pasler, Glenn Stanley, Thomas Christensen, Barbara H. Haggh, Robert Balchin, Laurence Libin, et al. 1980. "Musicology". In. The New Grove dictionary of music and musicians (Vol. 12: 836-863). Hong Kong: Península Publ. Lim. doi: 10.1093/gmo/9781561592630.article.46710

Dudeque, Norton. 2004. "Resenha - Sobre Harmonia de Arnold Schoenberg". PER MUSI-Revista Acadêmica de Música 9: 114-123.

Fernandes, José N. 2004. "Normatização estrutura e organização do ensino da música nas escolas de educação básica do Brasil: LDBEN/96, PCN e currículos oficiais em questão". Revista da ABEM 10: 75-87. 
Fernandes, José N. 2007. "Pesquisa em educação musical: situação do campo nas dissertações e teses dos cursos brasileiros (II)". Revista da ABEM 16: 95-98.

Fernandes, José N. 2014. “Educação musical internacional e comparada: uma introdução”. Debates - UNIRIO 13: 51-58.

Fernandes, José N. 2016. Música nas escolas públicas cariocas. Rio de Janeiro: Edição do autor.

Figueiredo, Sérgio L. F. de. 2010. Considerações sobre a pesquisa em educação musical. In Horizontes da Pesquisa em Música. Organizado por Vanda L. B. Freire, 155-175. Rio de Janeiro: 7Letras.

Franco, Maria Laura P. B. 2012. Análise de conteúdo. Brasília: Líber Livro.

Galizia, Fernando Stanzione. 2009. "Educação musical nas escolas de ensino fundamental e médio: considerando as vivências musicais dos alunos e as tecnologias digitais". Revista da ABEM 21: 76-83.

Ibarretxe, Gotzon. 2006. "El conocimiento científico en investigación musical". In Introducción a la investigación en Educación Musical. Editado por Maravillas Díaz, 9-30. Madrid: Enclave Creativa.

Libâneo, José Carlos. 1985. Democratização da escola pública: a pedagogia crítico-social dos conteúdos. 2aㅡ ed. Coleção educar. São Paulo: Loyola.

Libâneo, José Carlos, e Akiko Santos. 2010. Educação na era do conhecimento em rede e transdisciplinaridade. 3a ed. Campinas: Alínea.

Lima, Sônia Albano de. 2000. “A Educação profissional de música frente à LDB № 9394/96". Revista da ABEM 5: 39-44.

Loureiro, Alícia Maria A. 2003. O ensino de música na escola fundamental. Campinas: Papirus.

Magrini, James. 2012. "Existentialism, Phenomenology and Education". Philosophy Scholarship 7 (1): 1-4. Available in: <https://dc.cod.edu/cgi/viewcontent.cgi?article=1031\&context=philosophypub> Set. 2017.

Major, Claire Howell, end Maggi Savin-Baden. 2010. An Introduction to Qualitative Research Synthesis: Managing the information explosion in social science research. New York, NY: Routledge.

Mateiro, Teresa. 2009. "Uma análise de projetos pedagógicos de Licenciatura em Música". Revista da ABEM 22: 57-66.

Mateiro, Teresa, e Jusamara Souza (Orgs.). 2014. Práticas de ensinar música: legislação, planejamento, observação, registro, orientação, espaços, formação. Porto Alegre: Sulina.

Nettl, Bruno. 2010. "Music Education and Ethnomusicology: A (usually) Harmonious Relationship". Min-Ad: Israel Studies in Musicology Online 8 (1): 1-9. Disponível em: <http://www.biu.ac.il/hu/mu/minad/index.htm> Out. 2017.

Penna, Maura. 2002. Professores de música nas escolas públicas de ensino fundamental e médio: uma ausência significativa. Revista da ABEM 7: 7-19.

Penna, Maura. 2008. Caminhos para a conquista de espaços para a música na escola: uma discussão em aberto. Revista da ABEM 19: 57-64.

Pereira, Marcus Vinícius M. 2014. "Licenciatura em música e hábitos conservatorial: analisando o currículo". Revista da ABEM 22 (32): 90-103.

Pereira, Eliton P. R. 2017. "Pesquisas de Estado da Arte na Educação, na Música e na Educação musical". Artigo apresentado no XVII SEMPEM - Seminário Nacional de Pesquisa em Música da UFG \& I Seminário 
Nacional FLADEM - Brasil, Goiânia, Setembro 1-14. Disponível em: <https://mestrado.emac.ufg.br/n/31464-sempem-anais-on-line> Out. 2017.

Pereira, Eliton P. R. 2018. "As 300 teses em educação musical produzidas no Brasil até 2017". Artigo apresentado no XV Encontro Regional Centro-Oeste da Associação Brasileira de Educação Musical Educação musical em tempos de crise: percepções, impactos e enfrentamentos, Goiânia, Outubro 1-26. Disponível em: <http://abemeducacaomusical.com.br/conferencias/index.php/co2018> Dez. de 2019.

Pereira, Eliton P. R. 2019a. "A educação musical no Brasil: temáticas, concepções e linhas investigativas". Tese de Doutoramento em Educação. Universidade de Santiago de Compostela. Disponível em: <minerva.usc.es/xmlui/handle/10347/20495/> Dez. de 2019.

Pereira, Eliton P. R. 2019b. "Instrumentos Para Revisão da Produção Científica em Educação musical”. Artigo apresentado no XXIV Congresso da Associação Brasileira de Educação musical Educação musical em tempos de crise: percepções, impactos e enfrentamentos. Campo Grande, MS - novembro 1-13. Disponível em: <http://abem-submissoes.com.br/index.php/xxivcongresso/2019> Dez. de 2019.

Pereira, Eliton P. R. 2020. "Concepções pedagógicas da educação musical brasileira: relações com os campos da Educação e da arte-educação". Revista OPUS 26 (1): 1-21. Doi: 10.20504/opus2020a2601

Pires, Nair, e Ângela I. L. de F. Dalben. 2013. “Música nas escolas de educação básica: a produção acadêmica dos cursos de Pós-Graduação Stricto Sensu no Brasil (1972-2011)”. Revista OPUS 19 (2): 171-208.

Sampieri, Roberto H., Carlos F. Collado, e María de P. B. Lucio. 2013. Metodologia de Pesquisa. Coleção métodos de pesquisa. 5a ed. Porto Alegre: Penso.

Sánchez Gamboa, S. 2012. Pesquisa em Educação: métodos e epistemologias. 2a ed. Chapecó: Argos.

Santos, Cristina Bertoni dos. 2012. "Aula de música e escola: concepções e expectativas de alunos do ensino médio sobre a aula de música da escola". Revista da ABEM, 20(27), 79-92.

Santos Filho, José C. dos, e Silvio S. Gamboa. 2013. Pesquisa Educacional: quantidade-qualidade. São Paulo: Cortez.

Saviani, Dermeval. 2013. História das ideias pedagógicas no Brasil. 4ạ edição. Campinas, SP: Autores associados.

Silva, Rafael Rodrigues da. 2013. Gestão de sala de aula na Educação musical escolar. Revista da ABEM 21(31): 63-76.

Sobreira, Silvia Garcia. 2014. "Conexões entre Educação musical e o campo do Currículo". Revista da ABEM 22 (33): 95-108.

Solomon, Leonardo. 2015. A outra história: os discursos da New Musicology e sua aplicação nas didáticas de história da música. Curitiba: Prismas.

Souza, Ruth C. C. R. de, e Solange M. O. Magalhães (Orgs.). 2011. Pesquisas sobre professores: métodos tipos de pesquisa, temas, ideário pedagógico e referenciais. Goiânia: Editora da PUC Goiás.

Swanwick, Keith. 1992. "Music education and Ethnomusicology". British Journal of Ethnomusicology 1: 137144.

Tomás, Lia V. 2015. A Pesquisa Acadêmica na Área de Música: Um Estado da Arte (1988-2013). 1ํVol. Série Pesquisa. Porto Alegre: ANPPOM. 